


\title{
Yeguas del Apocalipsis: cultura loca y neoliberalismo en el Chile de Casa Particular
}

Florencia San Martín

Candidata a doctora en Historia del Arte, Rutgers University, EEUU. Florenciasanmartinriutort@gmail.com

\section{Resumen}

En 1990, coincidiendo con el fin de la dictadura en Chile, el Museo Nacional de Bellas Artes celebró el retorno de la libertad de expresión mediante una emblemática exposición titulada Museo Abierto. Sin embargo, aún en dicho espacio de libertad creativa, una obra fue censurada por su contenido travesti, lumpen y racialmente disidente. Se trataba de Casa Particular, video documental realizado en 1989 por las Yeguas del Apocalipsis (Pedro Lemebel y Francisco Casas) en colaboración con Gloria Camiruaga. Desde el punto de partida de Casa Particular, en este artículo se analizan algunas de las performances realizadas entre 1988 y 1996 por las Yeguas, colectivo que abordó las relaciones entre el sida, los derechos humanos y la disidencia sexual, racial y económica, para visibilizar, mediante sus prácticas performáticas, la continuación del orden hegemónico cultural de la dictadura en la transición neoliberal.

Palabras claves: Yeguas del Apocalipsis, neoliberalismo, sexualidades disidentes, transición

\begin{abstract}
In 1990, coinciding with the end of the dictatorship in Chile, the National Museum of Fine Arts celebrated the return of freedom of expression through an emblematic exhibition entitled "Museo Abierto" (Open Museum). However, even in this space of creative freedom, a work was censored for its transvestite, lumpen and racially dissident content. It was Casa Particular, a documentary video made in 1989 by Las Yeguas del Apocalipsis (Pedro Lemebel and Francisco Casas) in collaboration with Gloria Camiruaga. From the point of view of Casa Particular, this article analyzes some of the performances carried out between 1988 and 1996 by Las Yeguas. This group addressed the relationships between AIDS, human rights and sexual, racial and economic dissidence to make visible, through its performance practices, the continuity of the cultural hegemonic order of the dictatorship in the neoliberal transition.
\end{abstract}

Keywords: Yeguas del Apocalipsis, neoliberalism, dissident sexualities, transition

El 6 de septiembre de 1990, a seis meses de retornada la democracia a Chile, el Museo Nacional de Bellas Artes (MNBA) inauguró la exposición Museo Abierto. Reuniendo casi 400 obras, muchas de ellas censuradas previamente durante la dictadura cívico-militar (19731990), la exposición fue organizada por el artista y militante del Partido Comunista (PC), Nemesio Antúnez (Santiago 1918-1993). Considerada como hito cultural por haber sido el primer evento institucional que luego de diecisiete años de represión se enmarcaba en el tema de la libertad de expresión, Museo Abierto contó con un catálogo paradójicamente 
didáctico y formalista, con un listado de los trabajos exhibidos divididos materialmente en las secciones de fotografía, video, pintura, escultura, grabado e instalación (fig. 1). "Luego de muchos años de estar cerrado o semicerrado, el museo será un espacio abierto para todos los artistas provenientes de todos los estilos, generaciones, formas de expresión y técnicas" (Museo Abierto, 1990), escribió en el catálogo Antúnez, que entonces volvía del exilio y retomaba la dirección del MNBA ${ }^{1}$. Así, como el título de la exposición sugería, el museo se instalaba como lugar autónomo y sin censura, siguiendo con las políticas de inclusión de un país ahora democrático, cuya agenda intentaba recuperar la libertad que la dictadura cívico-militar había brutalmente desmantelado.

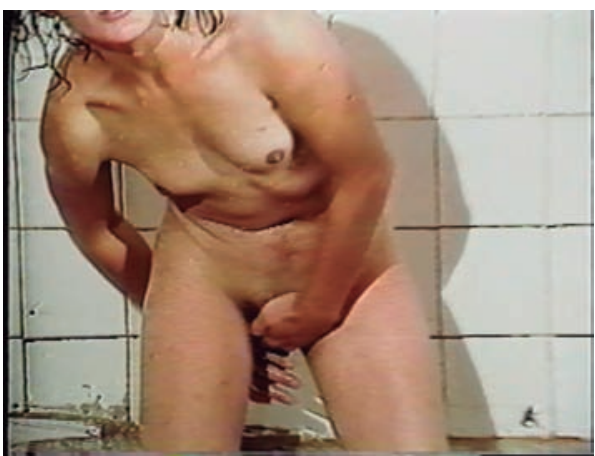

Fig. 2. Video Casa Particular, Gloria CAmiruaga, 1990 Colección Audiovisual, CeDoc Artes Visuales Cortesía del Centro de Documentación de las Artes Visuales y de Rocio Ramos Camiruaga (2)

Pero a pesar de las buenas intenciones de Antúnez -y de las expectativas de inclusión de la llamada vuelta a la democracia-, a pocos días de inaugurada la exposición una obra fue censurada por mostrar el pene de una travesti mientras se duchaba en un prostíbulo lumpen de Santiago (fig. 2). Se trataba de un fragmento de Casa Particular, un video documental realizado por las Yeguas del Apocalipsis, dúo de arte sexualmente disidente formado por los escritores Pedro Lemebel (Santiago, 1952-2015) y Francisco Casas (Santiago, 1959), en colaboración con la documentalista Gloria Camiruaga (Santiago 1941-2006). ¿Por qué dentro de todos los trabajos exhibidos, de los cuales muchos representaban abiertamente la violencia de las prácticas de tortura y desaparición ocurridas durante el régimen militar, la exhibición del pene de una travesti seguía siendo inapropiada y entonces objeto de censura? ¿Debía la disidencia sexual, específicamente cuando venía

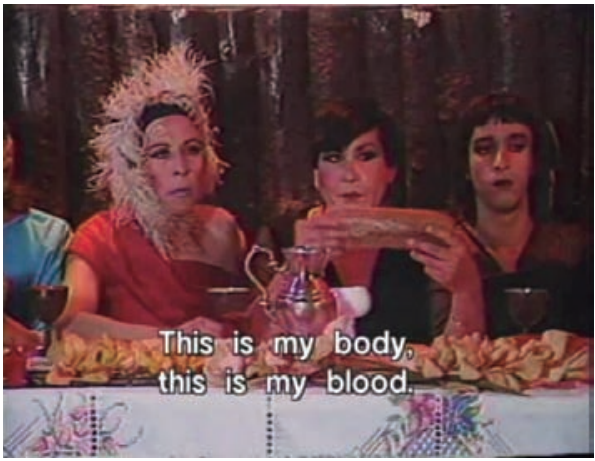

Fig. 3. Yeguas del Apocalipsis. La última Cena de San Camilo, 1989. Performance documentada por Gloria Camiruaga en Casa Particular, 1989. Cortesía de D21 Proyectos de Arte de la voz y el cuerpo del sujeto lumpen y racialmente discriminado, aún autocensurarse en la transición? Desde el punto de partida de Casa Particular, en este artículo se analizan ciertas estrategias simbólicas y estéticas de resistencia de las Yeguas frente al legado que dejó la dictadura en la institución del arte durante los primeros años que precedieron al triunfo del No, referéndum nacional realizado el 5 de octubre de 1988 donde la mayoría decidió que Pinochet debía salir de la presidencia. Así, en lo que sigue me referiré, tomando como marco teórico la propia crónica lemebeliana, a la continuidad de dicho legado respecto a la discriminación social y

1 Fundado el 18 de septiembre de 1880 en el Parque Quinta Normal, para el centenario de la independencia de Chile en 1910, el MNBA se trasladó al edificio neoclásico diseñado por Emile Jéquier ubicado en el Parque Forestal. En 1969, el nuevo presidente de Chile, el socialista Salvador Allende, nombró a Antúnez como director del museo, enfocándose este segundo en la restauración de la institución, creación de la Sala Matta para exposiciones temporales y la ampliación del programa hacia otras disciplinas como la música, la danza, el teatro y el cine. Luego del golpe de Estado en 1973, la junta expulsó a Antúnez del museo y del país nombrando a la escultora Lily Garafulic como directora, cargo que asumió desde 1974 , siendo reemplazada en 1978 por Nena Ossa. En 1990, una vez regresada la democracia, Antúnez fue relecto director del museo en el contexto de los gobiernos concertados, inaugurados por el demócrata Cristiano Patricio Aylwin. 
cultural y al sistema patriarcal, donde lo masculino heterosexual prevalece sobre las diversidades de lo femenino y las formas heterodoxas de masculinidad. Lo que propongo, en suma, es la visibilización de una mirada crítica respecto a la institución patriarcal y elitista del arte en relación con la continuidad del modelo liberal en el Chile del posplebiscito, resultando la exposición Museo Abierto paradigmática por haber sido la primera organizada en la llamada democracia y, a la vez, la primera en retomar, aunque contraria a sus aspiraciones de inclusión, la censura.

Realizado en 1989, Casa Particular estaba compuesto de dos performances: La última cena de San Camilo (fig. 3) y Malena canta un tango (fig. 4), además de una serie de testimonios de trabajadoras sexuales travestis documentados por Camiruaga y editados en conjunto con Lemebel y Casas (fig. 5). Ambos, las performances y los testimonios, tuvieron lugar en prostíbulos lumpen y sus alrededores en la calle San Camilo, ex-centro de comercio sexual ubicado en el centro de Santiago. En uno de los testimonios, una travesti narraba su experiencia con el contagio del sida a finales de los ochenta, y luego, parafraseando a Lemebel, aparecía duchándose en un prostíbulo sin poder contener el pene tras las piernas, desmantelando la precariedad de la cirugía artesanal (Lemebel, 1996: 36) de la biología femenina. Como escribe Lemebel (1996) en su crónica dedicada a este episodio, "Con tanto foco y calor, con ese narciso tibio a las puertas del meollo, el truco se suelta como un elástico nervioso, como un péndulo sorpresa que desborda la pose virginal, quedando registrado en video el fraude quirúrgico de la diosa” (p. 36). El pene de la travesti llenando la pantalla una y otra vez por el loop del video causó, según relata Lemebel en La muerte de la Madonna, un gran escándalo y muecas sarcásticas en un grupo

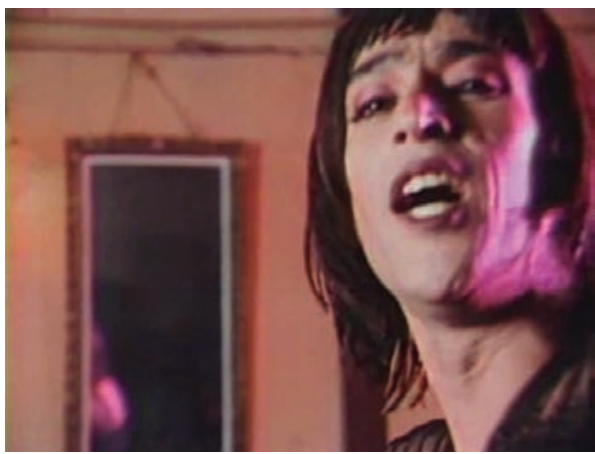

Fig. 4. Francisco Casas. Malena Canta un Tango, 1989. Performance documentada por Gloria Camiruaga en Casa Particular. Cortesía de Centro de Documentación de las Artes Visuales y Rocío Ramos Camiruaga.

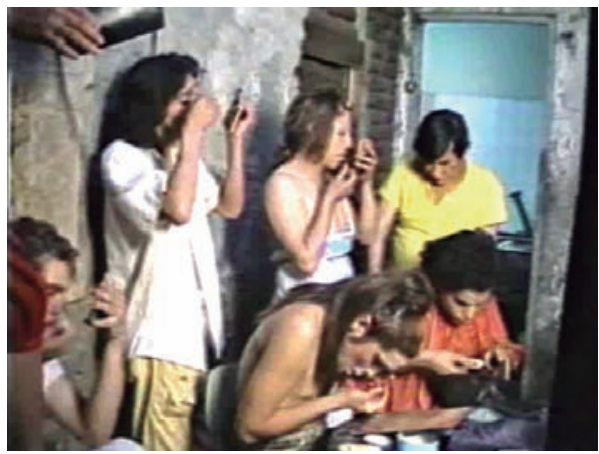

Fig. 5. Gloria Camiruaga. Casa Particular, 1989. Cortesía de D21 Proyectos de Arte de escolares que visitaba Museo Abierto, cuestión que llevó a los guardias a llamar a Antúnez quien, al presenciar el alboroto, ordenó la reprobación del video "dando disculpas" (p. 38) diciendo "que en ese caso era aplicable la censura" (p. 38).

El testimonio de la travesti funciona, me gustaría argumentar aquí, como resistencia frente a la hegemonía patriarcal con la cual se llevó a cabo la censura de la obra. Para entender dicha estrategia resulta significativo pensar el testimonio como antecedente al tono con que Lemebel escribe Loco afán: crónicas de sidario (1996), donde, como argumenta Jean Franco (2004), "se transparenta la necesidad de nombrar-nombrar víctimas, nombrar muertos y así enfrentarse con historias que dan a la homosexualidad un lugar en la política" (p. 17). No se trata, ni en Loco Afan ni en la serie de testimonios de Casa Particular, de la victimización o la mirada prejuiciosa a las víctimas del sida, tendencia con la que se discriminó a los sujetos infectados por la plaga divulgada en el país a 
principios de los ochenta; plaga que, según explica Lemebel (1996), "fue el resultado del tufo mortuorio de la dictadura" (p. 4)². Más bien, el testimonio tiene que ver con el deseo de recordar a las víctimas de la enfermedad dándoles lugar como testigos, revelando la variedad de subjetividades travestis que desmitifican los estereotipos de los cuerpos disidentes, contestatarios y colectivos, pero no por eso generalizados.

Cuando el discurso hegemónico heterosexual y los estereotipos genéricos emanados de la derecha conservadora chilena podrían no sorprender, lo cierto es que los prejuicios de la izquierda frente a los diferentes tipos de masculinidad podrían parecer, al menos a primera vista, menos coherentes que su contraparte. Consciente de lo anterior no solo a nivel teórico, sino que también a través de su propia experiencia -a mediados de los ochenta Lemebel fue expulsado del colegio donde enseñaba artes plásticas por su condición homosexual-, en 1986, en un masivo acto de izquierdas en el Estadio Chile, Lemebel leyó por primera vez su famoso manifiesto donde, entre otras cosas, se refería a la hegemonía de la izquierda ortodoxa en cuanto a la diversidad del género. Titulado Hablo por mi diferencia, en aquella ocasión Lemebel utilizó por primera vez el testimonio como recurso discursivo y estético, criticando la homofobia de la izquierda desde un relato donde la literatura se cruzaba con la performance y el activismo. Como indica Fernanda Carvajal (2011), "Lemebel desafió a la izquierda marcando la irrupción de un rostro y acto de habla específicos. "No necesito disfraz -dice Lemebel- Aquí está mi cara / Hablo por mi diferencia”" (p. 19).

En Casa Particular, el cuerpo desnudo de la Madonna travesti, es decir, su diferencia documentada por la cámara de Camiruaga y decididamente no autocensurada por Lemebel y Casas en la edición, enfatiza las formas de hombría no hegemónicas que Lemebel reclama en Hablo por mi diferencia, a la vez que nos hace pensar en Antúnez, un artista militante del PC exiliado por el régimen militar, como paradigma de la izquierda patriarcal celebrada por el Estado concertado y sus instituciones, en este caso el Museo Nacional de Bellas Artes. Así, se podría pensar también que la censura de Casa Particular significa más bien una interrupción que una expulsión. Como explica Carvajal (2011) al analizar el intento fallido de las Yeguas de levantar un lienzo con la consigna "Homosexuales por el cambio" en un acto cultural del PC realizado en 1989 en el Estadio Santa Laura para apoyar la candidatura de Patricio Aylwin -y digo fallido, pues Lemebel y Casas fueron obligados a bajar del escenario por miembros de las juventudes comunistas, siendo además reprimidos por Mariana Aylwin, hija del candidato presidencial y famosa política chilena- "no es posible expulsar a aquel que nunca ha pertenecido" (p. 15). Por lo mismo, las Yeguas siempre se refirieron a su trabajo como manifestaciones intrusas en el espacio público, correspondiendo dicha intrusidad a la interrupción de lo cultural y lo socialmente aceptado. Así, vale la pena recordar que para Museo Abierto no hubo una selección a priori de obras, por lo que dichas obras nunca pertenecieron. En un esfuerzo por desmantelar las políticas de censura del régimen cívicomilitar, el equipo curatorial del museo liderado por Antúnez aceptó todas las aplicaciones y luego, cuando exhibidas, contradictoriamente a su política de inclusión censuró, mediante el juicio moral, aquella que no le pareció correcta, a saber, Casa Particular.

La parodia a las estrellas de Hollywood es también constituyente respecto a la noción de testimonio de Casa Particular. Ejemplificado en este caso por una travesti que, habiendo adoptado el seudónimo de Madonna en honor a la cantante pop estadounidense, había sido la primera mapuche en morir de sida a finales de los ochenta en Chile, "la loca busca imitar a la cantante, intenta reproducirla, pero su origen mapuche la convierte en una mala copia, más aún, su origen y el modelo que intenta reproducir se vuelven incompatibles"

2 Para más sobre la relación entre el sida y la dictadura en la escritura de Lemebel, ver los ensayos reunidos en Blanco, Fernando, Reinas de otro cielo: modernidad y autoritarismo en la obra de Pedro Lemebel (LOM Ediciones; Denison University: 2004). 
(Tocornal, 2015, p. 9). Considerando el vínculo entre estos dos grupos marginados -el del género y el de la etnia- en Loco Afán, Lemebel parodia la imposibilidad de alcanzar el estereotipo cultural, es decir, las exigencias de la estética promovida por el mercado, imposibilidad que se representada en la idea de ser Madonna por un día. Y dicho deseo, me gustaría proponer aquí, es constituyente del programa estético de las Yeguas, en un sentido más amplio, pues la loca de las Yeguas, como explica Casas, "se resiste y al mismo tiempo quiere pertenecer al maintream cultural" (Galende, 2009, p. 170). La cultura loca en Chile, entonces, cuando proviene del cuerpo travesti doblemente marginalizado por su raza y economía cultural, implica el deseo que asume la identidad local y regional, al tiempo que parodia la idiosincrasia de las élites respecto a la cultura occidental.

Así, el 30 de septiembre de 1990, esto es, a tres semanas de inaugurada Museo Abierto y tomando en cuenta la noción de ser Madonna por un día, las Yeguas del Apocalipsis realizaron una performance sin previa autorización que respondió a la censura de Antúnez de Casa Particular.

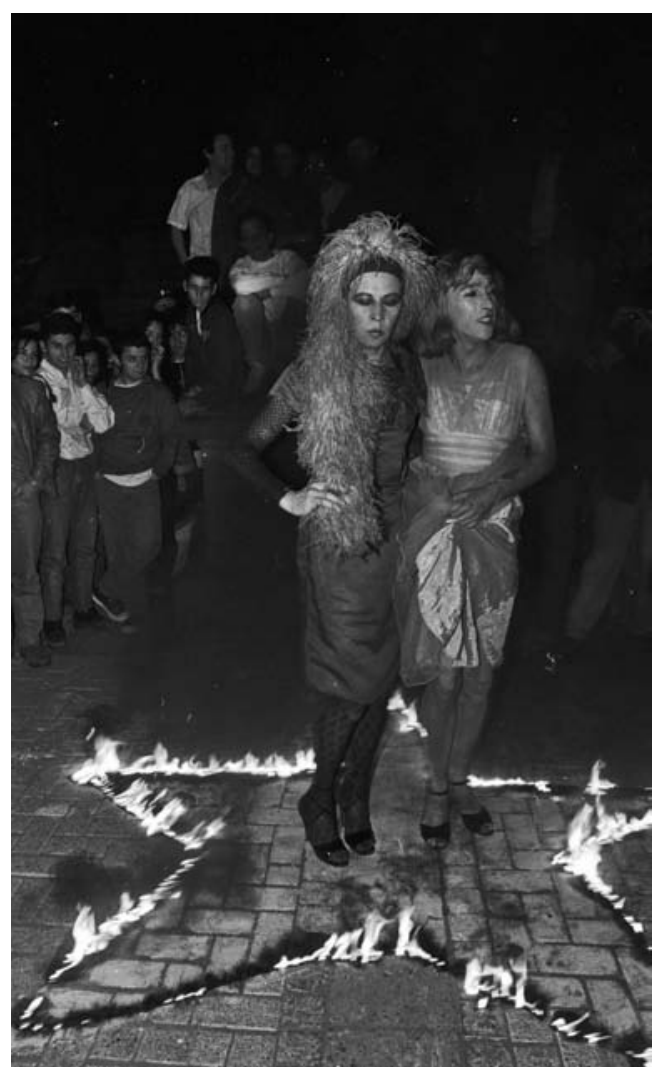

Fig. 6. Yeguas del Apocalipsis. Estrellada II, 1990. Cortesía de D21 Proyectos de Arte (2) Titulada Estrellada II, Casas y Lemebel interpretaron los roles de Dolores del Río y Rita Hayworth, respectivamente, dibujando estrellas de neopren, la llamada droga de los pobres, en el pavimento del frontis del MNBA (fig. 6). Situándose al centro de una gran estrella, las Yeguas encendieron fuego en sus bordes, dando inicio a un juego paródico de binarios, donde la superficie del vestuario -las medias blancas y las medias negras- y el cuerpo racial de las locas llamaron la atención sobre las diferencias múltiples al interior de la homosexualidad, calladas por el museo que, paradójicamente, se decía abierto. Con las puertas del museo ya cerradas a las ocho de la noche, que fue cuando se llevó a cabo la acción, Estrellada II fue a su vez una cita a la performance Estrellada $I$, realizada un año antes en la calle San Camilo (fig. 7).

En esta primera versión, Lemebel y Casas, semidesnudos, pintaron sus cuerpos con símbolos en blanco y negro, dibujando estrellas fluorescentes en el pavimento mediante la técnica del esténcil. Con una audiencia formada por travestis, prensa alternativa, vecinos de la calle San Camilo

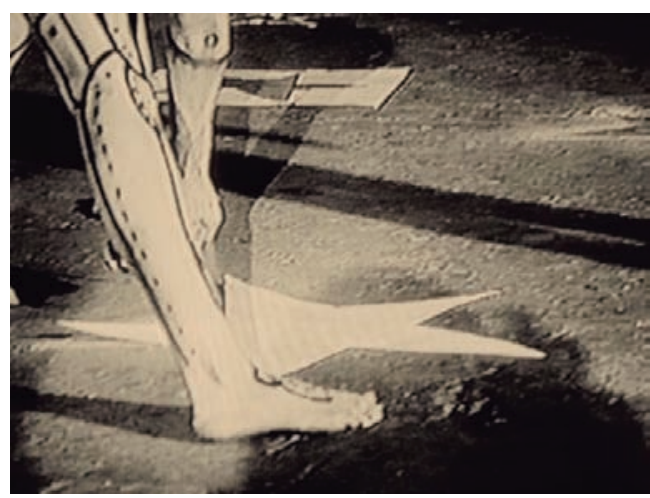

Fig. 7. Yeguas del Apocalipsis. Estrellada I, 1989. Cortesía de D21 Proyectos de Arte 
e intelectuales de la contracultura -entre ellos, la fotógrafa Paz Errázuriz (Santiago, 1944) que documentó la acción-, la performance se realizó el 26 de noviembre de 1989, el mismo día del cumpleaños de Pinochet. Esa noche, el Frente Patriótico Manuel Rodríguez, grupo paramilitar de la extrema izquierda, activo entre 1983 y 1990, provocó un apagón en la ciudad dando aún más brillo y glamour -como bien lo soñara la travesti que desea ser Madonna por un día- a las estrellas fluorescentes en la marginal calle de San Camilo. Así, cuando la ciudad entera se había tornado a negro, San Camilo seguía encendida como un escenario de luces no lejano, metafórica y paródicamente, al Broadway o al Hollywood estadounidense. Según Lemebel (1996):

La intervención escenografiaba un homenaje, una estrellada nocturna desplegada en el cemento sucio. Una parodia de Broadway en el barro de la sodomía latinoamericana... Así, el barrio pobre por una noche se soñó teatro chino y vereda tropical del set cinematográfico. Un Malibú de latas donde el universo de las divas se espejeaba en el cotidiano tercermundista. Calle de espejos rotos, donde el espejismo enmarcado por las estrellas del suelo recogía la mascarada errante del puterío anal santiaguino (pp. 35-36).

Pero en Estrellada I las Yeguas aluden además al sida, cuestión que formalmente se puede observar mediante la aplicación del esténcil que, como la fotografía, juega con las zonas de exposición y de reserva, en este caso como metáfora a la relación positivo/negativo. Vale la pena recordar que el sujeto y su relación con el sida, al que aluden las Yeguas tanto en Estrellada I como en Estrellada II, pertenece y representa lo lumpen, notando cómo las diferencias económicas y sociales en el mundo homosexual influyeron en las posibilidades de la vida -o de su alargamiento- una vez instaurada la dictadura en Chile. Dicho fenómeno se visibiliza en La noche de los visones (o la última fiesta de la Unidad Popular), la crónica con la que Lemebel recuerda una fiesta gay organizada por una humilde vendedora de pollos de la vega Central para celebrar el año nuevo de 1972. Al evento, como relata Lemebel mediante el apoyo de una vieja fotografía, asistieron toda clase de travestis, como era común durante el gobierno de la Unidad Popular (1970-1973), cuestión que cambió luego del golpe y que se acentuó con la llegada del sida en los ochenta. Como escribe Lemebel (1996):

Todo el mundo estaba invitado, las locas pobres, las de Recoleta, las de mediopelo, las del Blue Ballet, las de la Carlina, las callejeras que patinaban la noche en la calle Huérfanos, la Chumilou y su pandilla travesti, las regias del Coppelia y la Pilola Alessandri. Todas se juntaban en los patios de la UNCTAD para imaginar los modelitos que iban a lucir esa noche (p. 12).

Así, a lo largo de sus crónicas, Lemebel da cuenta de cómo el gay de clase acomodada se comienza a divulgar como una moda, distanciándose de la heterogeneidad que recurría antes de la dictadura, transfiguración que Jean Franco (2004) explica de la siguiente manera:

En el mercado neoliberal, la cultura gay de clase acomodada se convierte en moda y los jóvenes que se venden en este mercado ya no se sienten obligados a asumir una masculinidad prepotente, sino al contrario asumen la posición pasiva, así ejemplificando la suave dominación de una sociedad que emplea incentivos económicos en vez de la represión disciplinaria. (p. 58).

Dicha suavidad con que opera el neoliberalismo se visibiliza en las performances de las Yeguas realizadas en los prostíbulos de San Camilo y sus alrededores, siendo luego desplazadas mediante la cita -como en el caso de Estrellada II- o la documentación -como en el caso de las performances y los testimonios de Casa Particular- al Museo de Bellas Artes, rechazando así la pasividad del gay neoliberal en pos del sujeto políticamente activo que se manifiesta tanto cultural como económicamente disconforme. No hay allí networking, 


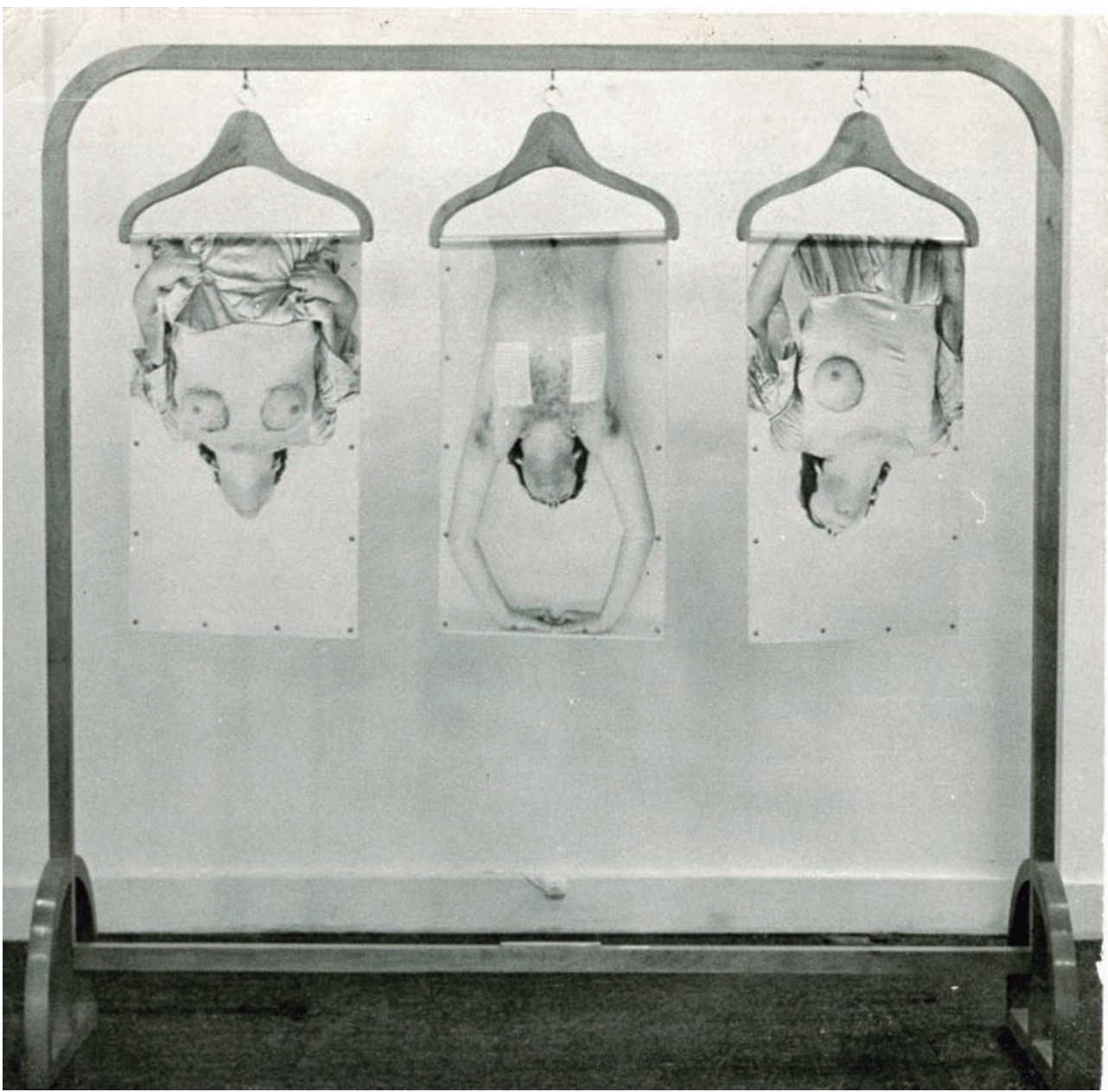

Fig. 8. Carlos Leppe, El Perchero, 1975. Cortesía de D21 Proyectos de Arte.

interactividad, ni zonas de libre de mercado, sino una serie de inflexiones donde el sujeto económica, étnica y sexualmente diferente se resiste a los modelos dominantes. Al mismo tiempo, "para Lemebel y Casas, que vienen de las clases bajas, la pobreza no es un lugar exótico (...). La marginalización y la pobreza son parte de sus propias experiencias" (Palaversich, 2004, p. 244). En este sentido, como continúa Palaversich (2004), "la cultura loca en la escritura de Lemebel y el trabajo de las Yeguas no es equivalente a la cultura drag en los Estados Unidos, donde esta manifestación ha dejado de ser un modo de vida y se ha convertido en una mera empresa comercial" (p. 257).

Como se ha analizado hasta ahora, el testimonio y la idea de ser Madonna por un día aparecen como tropos recurrentes en las performances de las Yeguas en torno a Casa Particular, a lo que podemos sumar la parodia del signo religioso considerando el antecedente, pero además las diferencias, entre las Yeguas y el artista chileno homosexual Carlos Leppe (Santiago, 1952-2015). Respecto a la figura de Leppe como antecedente, cuestión atribuida principalmente por Nelly Richard, en Pechero (1975), tres fotografías del artista 
cuelgan de una estructura metálica como prendas de ropa, mostrando y ocultando a la vez ciertas partes de su cuerpo masculino (fig. 8). Cuando la pose, sobre todo en la fotografía central, alude a la imagen de Cristo crucificado, también lo hace respecto a las técnicas de tortura utilizadas en los sitios de detención durante el régimen militar. La primera ocasión en que el cuerpo desnudo o semidesnudo del sujeto sexualmente disidente interrumpía en la escena de neovanguardia local, en Perchero, según explica Nelly Richard (2006):

Leppe pone en escena un yo parodiante cuya estrategia de las apariencias usa disfraces de identidad para jugar con una corporalidad sexualmente reversible y metafórica (...) Desde el desnudo masculino que viste la retórica de lo femenino como cadena de artificios, el cuerpo de Leppe se postula como un cuerpo de citas: una zona de referencias cosméticas, fotogénicas y teatrales a modelos corporales que deconstruyen y reconstruyen su identidad en la diferencia y la alteridad (pp. 80-81).

A la luz de la descripción de Richard, se podría pensar también en parodia al signo religioso en La Última Cena de San Camilo, una de las dos performances realizadas por las Yeguas y documentadas en Casa Particular. Citando La Última Cena de Leonardo, en la versión travesti latinoamericana del colectivo, el rol de Jesús es interpretado por la Doctora, la dueña del prostíbulo, mientras que los apóstoles son interpretados por las Yeguas y trabajadoras sexuales de San Camilo. Hasta ahora, tanto Perchero como La Última Cena de San Camilo aluden al signo católico patriarcal impuesto por la Colonia y aliado al discurso dictatorial de Pinochet. Cuando en el caso de Leppe dicha relación se daba por una doble cita que interpelaba tanto al ícono religioso universal como a la experiencia del cuerpo torturado local, en La Última Cena de San Camilo, dicha coyuntura es una vez más de carácter doble, con ambos, Cristo y Pinochet, personificados por la Doctora. Sentada al centro de la mesa con los discípulos a su alrededor y a pocas semanas del plebiscito, ella, la Doctora, que es salvador espiritual y civil al mismo tiempo, dice: "Esta es la última cena de San Camilo, la última cena de este gobierno; este es mi cuerpo, esta es mi sangre". Así, mediante la denuncia y la parodia, el dúo pone en escena los vínculos ocultos que existieron entre la dictadura militar y el discurso religioso, criticando los procesos coloniales donde la religión ha tenido un papel protagónico en la enseñanza de valores culturales y morales europeos. Pero si bien es cierto que Leppe y las Yeguas comparten una mirada similar respecto a la relación entre religión y dictadura, y si bien también es cierto que en ambos casos el sujeto travesti critica los esencialismos sociales resignificando, como lo notó Richard (2006), "a la mujer sufriente en travesti y alcanzando así lo femenino performativo y estratégico” (p. 81), ambas prácticas representan subjetividades, necesidades y deseos de sujetos provenientes

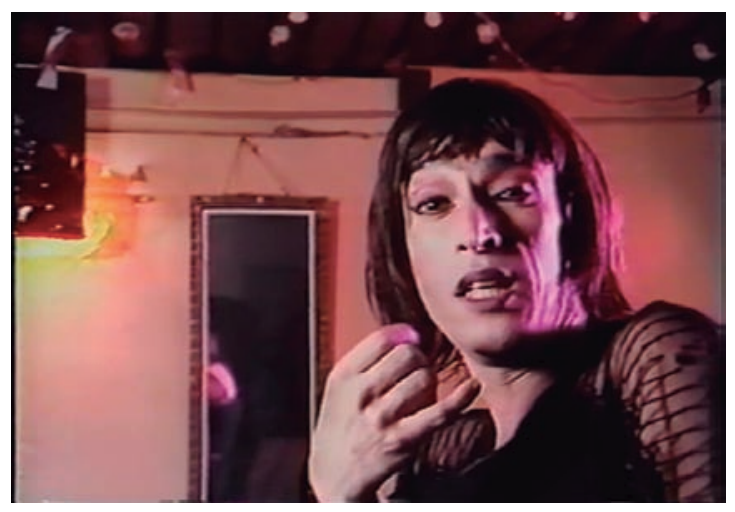

Fig. 9. Video Casa Particular, Gloria Camiruaga, 1990 Colección Audiovisual, CeDoc Artes Visuales Cortesía del Centro de Documentación de las Artes Visuales y de Rocío Ramos Camiruaga de clases diferentes, invitando al espectador a reconsiderar el problema que deviene de la generalización de las sexualidades disidentes. Una breve explicación respecto a la noción de melodrama presente en el trabajo de las Yeguas servirá para ahondar en lo anterior.

En La Última Cena de San Camilo, luego de que la Doctora interpreta la filiación entre la iglesia y el autoritarismo militar, se da inicio a una fiesta cruzada por el bolero y el alcohol. Celebrando la noticia del triunfo del No, que aun desde la mirada críptica de las Yeguas significaba el deseo de 
la libertad de expresión en un país brutalmente reprimido, las locas de San Camilo se embriagan para culminar la velada con la interpretación de Malena Canta un Tango, de Libertad Lamarque, por Casas (fig. 9). Así, la interpretación de una yegua borracha en el rol ya no de un apóstol travesti sino de la cantante y actriz argentina -una de las estrellas más destacadas del mundo del espectáculo latinoamericano-, representa al sujeto melodramático que hace eco a las subjetividades sufrientes y victimizadas relacionadas con la cultura de masas. Casas, en otras palabras, interpreta al bolero y no al pop, aunque la travesti desee, como hemos insistido, ser Madonna por un día. El bolero y la telenovela, en suma, más tienen que ver con la cultura de masas latinoamericana que con el pop o el drag, y es aquello, es decir, lo regional, lo que representan las Yeguas del Apocalipsis: las plumas, los trajes, las luces transfiguradas en el vestuario de otros nombres: las estrellas. En la novela Yo Yegua, de Francisco Casas, por ejemplo, donde a partir de un estilo barroco siempre al borde del derroche el autor se refiere a sus performances con Lemebel, Casas no deja de retratarse a sí mismo como Dolores del Río, tal como la travesti de Temuco se hacía llamar Madonna, y tal como el Casas se travestía de la diva mexicana en Estrellada II.

Pero volviendo al análisis de Richard sobre la influencia de Leppe en las performances de las Yeguas, el mismo Casas es enfático respecto a su negatividad:

Yo creo que el trabajo de Leppe es un trabajo apolítico, o que sencillamente trabaja para la derecha. El trabajo de la Nelly no nos parecía. Nos interesaba, pero no nos parecía, [pues] los objetos de deseo sobre los que ella trabajaba nos parecían inoportunos respecto a la contingencia política del momento. Había muchos trabajos que permitían que El Mercurio los tomara, los elevara y dijera oye, aquí hay arte experimental, aquí no ha pasado nada (Galende, 2009, p. 169).

Siguiendo la lectura de Casas, no resulta extraño asociarla con la de Willy Thayer respecto a la Escena de Avanzada, término acuñado por Richard en su libro Márgenes e Instituciones (1986). Thayer, en su ensayo El Golpe como consumación de la vanguardia (2003), de manera provocadora, en el buen sentido de la palabra, pues se trató de un texto que abrió el debate sobre cómo repensar la neovanguardia local en el periodo de transición, puso en relaciones de equivalencia tanto al golpe como a la Escena de Avanzada, indicando que la neovanguardia descrita autoritariamente, como argumenta el autor, por Nelly Richard, no representaría más que la repetición del golpe que tan brutalmente afectó la historia y la memoria de Chile (Thayer, 2003). De acuerdo o no con la noción autoritaria y fundacional de la vanguardia que observa Thayer en la escritura de Richard, tanto Thayer como Casas consideran dicha escena local, en la cual Leppe tuvo protagonismo, como lugar cercano a la agenda de la derecha, donde el arte se mantiene aislado a las demandas de, en este caso, las sexualidades disidentes del cuerpo racial, lumpen y politizado. Algo parecido ocurría, aunque con otras máscaras, en la exposición Museo Abierto, para lo que las Yeguas, mediante una performance en respuesta a la censura, demandaron la visibilidad de su política en el espacio de la cultura.

En los brumosos y celebratorios años en que comenzaba la transición temporal y no real, que como lo ha notado I. Avelar (2000) ocurrió durante la dictadura, con la transmutación del Estado a la privatización, las Yeguas optaron por el testimonio como

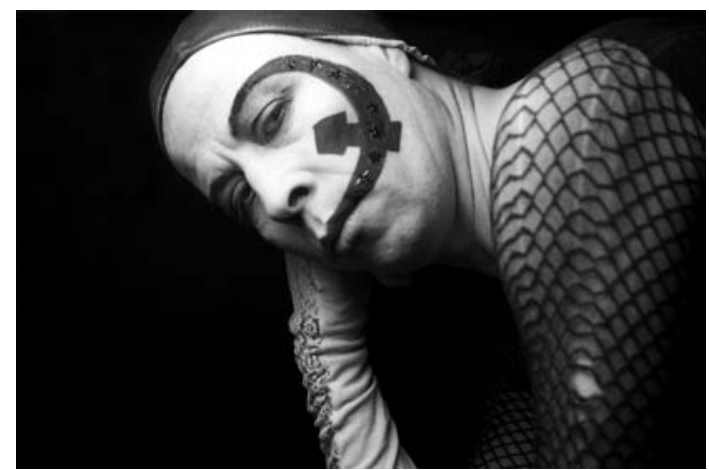

Fig. 10. Pedro Lemebel, Hablo por mi diferencia, 1986. Cortesía de D21 Proyectos de Arte 


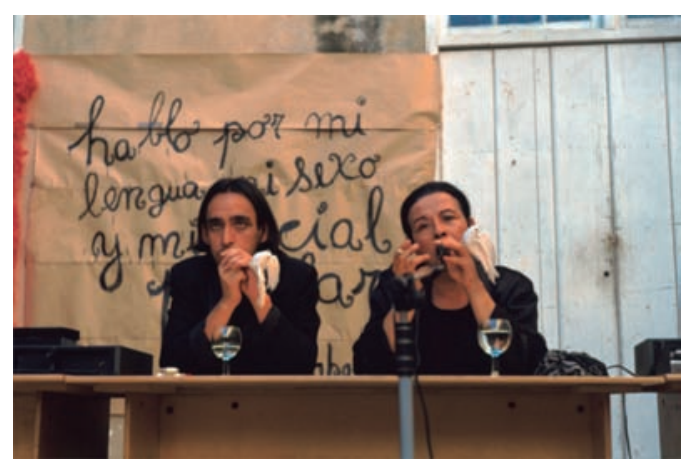

Fig. 11. Yeguas del Apocalipsis, Ejercicio de Memoria, 1997. Cortesía de D21 Proyectos de Arte. recurso estético, haciendo del propio cuerpo disidente la representación de sí mismo. Dicho de otro modo, el cuerpo es testigo de su deseo como copia sudaca del espectáculo hollywoodense, del melodrama ebrio y comunal, o del sujeto que milita una y otra vez su diferencia y su habla. Respecto a esto último, vale la pena recordar que Lemebel, que nació en un barrio marginal de Santiago a orillas del Zanjón de la Aguada y que creció en La Legua, una población emblemática de la delincuencia y el tráfico de drogas en Chile,

leyó por primera vez su manifiesto en 1986, con tacones y camisa de encajes, a la vez que maquillado teatralmente con la hoz y el martillo del PC (fig. 10). La diferencia melodramática, testimonial y sudamericana, nos dice Lemebel, y las performances de las Yeguas dentro y en contra de la institución del arte, conforman la identidad histórica y al mismo tiempo en movimiento que caracterizan la cultura loca: la esquina local de las Yeguas del Apocalipsis. Fue justamente visibilizando aquella esquina que, en 1997 en la Bienal de la Habana, el colectivo realizó su última intervención (fig. 11). Una conferencia performativa en la que, al tiempo en que se reproducía el manifiesto Hablo por mi diferencia, el espectador podía leer y, entonces, sentir la siguiente consigna en un lienzo tras los cuerpos de las Yeguas vestidos de negro: "Hablo por mi lengua, mi sexo y mi social popular". 


\section{Referencias bibliográficas}

Avelar, I. (2000). Alegorías de la derrota: la ficción postdictatorial y el trabajo del duelo. Santiago: Editorial Cuarto Propio.

Carvajal, F. (2011). Yeguas. En Centro Cultural La Moneda: Centro de Documentación

(Ed.), Ensayos sobre artes visuales: prácticas y discursos de los años 70 y 80 en Chile. Santiago: LOM.

Casas, F. (2004). Yo Yegua. Editorial Planeta. Santiago de Chile.

Franco, J. (2004). Estudio preliminar. Encajes de acero: la libertad bajo vigilancia.

Blanco, F. (Ed.), Reinas de otro cielo: modernidad y autoritarismo en la obra de Pedro Lemebel. (pp. 1122). LOM. Santiago de Chile.

Galende, F. (2009). Filtraciones II. Cuarto Propio. Santiago de Chile.

Lemebel, P. (1996). La noche de los visones (o la última fiesta de la Unidad Popular).

En Loco afán. Crónica de Sidario. LOM. Santiago de Chile.
Lemebel, P. (1996). La muerte de la Madonna. En Loco afán. Crónica de Sidario. LOM. Santiago de Chile.

Museo Abierto. (1990). Museo de Bellas Artes. Santiago de Chile.

Palaversich, D. (2010). "El cuerpo agredido de la homosexualidad proletaria y Loco Afán de Pedro Lemebel". En Blanco, F. y Poblete J. (Eds.). Desdén al infortunio. Sujeto, comunicación y público en la narrativa de Pedro Lemebel. (pp. 243-266). Cuarto Propio: Santiago de Chile.

Richard, N. (2006). Márgenes e instituciones: arte en Chile desde 1973. Metales Pesados. Santiago de Chile.

Thayer, W. (2000). El Golpe como consumación de la vanguardia. Revista Extremoccidente (N. $\left.{ }^{\circ} 2\right)$. Editorial Arcis: Santiago de Chile.

Tocornal, L. (2007). Una mirada a "la loca" de Pedro Lemebel: de figura privilegiada a figura paradigmática. (Tesis de posgrado). Universidad de Chile, Santiago. Recuperado de http://www. tesis.uchile.cl/tesis/uchile/2007/tocornal_c/pdf/ tocornal_c-TH.5.pdf 